\title{
Urinary NGAL is a Potential Biomarker for Early Renal Injury in Insulin Resistant Obese Non-Diabetic Children
}

\section{Running Head: Urinary NGAL in Insulin Resistant Obese Children}

Semra Şen ${ }^{1}$, Deniz Özalp Kızılay ${ }^{2}$, Fatma Taneli ${ }^{3}$, Çınar Özen ${ }^{4}$, Pelin Ertan $^{4}$, İpek Özunan ${ }^{4}$, Raziye Yıldız ${ }^{3}$, Betül Ersoy ${ }^{2}$ ${ }^{1}$ Department of Pediatrics, Celal Bayar University, School of Medicine, Manisa, Turkey

${ }^{2}$ Department of Pediatrics, Division of Pediatric Endocrionology, Celal Bayar University, School of Medicine, Manisa, Turkey

${ }^{3}$ Department of Medical Biochemistry, School of Medicine, Celal Bayar University, Manisa, Turkey.

${ }^{4}$ Department of Pediatrics, Division of Pediatric Nephrology, Celal Bayar University, School of Medicine, Manisa, Turke

What is already known on this topic?

Neutrophil gelatinase-associated lipocalin (NGAL) is one of the new biomarkers in detecting acute renal injury. NGAL was defined as an early renal injury biomarker in type $2 \mathrm{DM}$ too. Microalbuminuria has significant limitations in determining disease progression. Therefore, identification and validation of new biomarkers for early diagnosis of kidney injury may help to predict nephropathy and progression.

What this study adds?

This study reflects that obese children with normoalbuminuric insulin resistance without diabetes have higher urinary NGAL levels than those without IR and are at risk for early renal damage. Type 2 diabetes has an insidious clinical course. NGAL may be a marker of early renal damage in obese IR children before type 2 diabetes develops.

\footnotetext{
Abstract

Objective: Neutrophil gelatinase-associated lipocalin (NGAL) is one of the new biomarkers in detecting acute renal injury. There are studies showing the relationship between NGAL and renal injury in obese children. This study aimed to investigate whether the urinary levels of NGAL, kidney injury molecule-1 (KIM-1), and serum cystatin-C are increased in insulin resistance (IR) patients before the development of diabetes.

Methods: Our cross-sectional, case-control study included non-diabetic obese children and adolescent patients with IR and an non-diabetic obese control group with no IR, who applied to the Pediatric Endocrinology outpatient clinic of Manisa Celal Bayar University between 2017-2018. Those with diabetes mellitus, known renal disease were excluded. NGAL and creatinine levels were evaluated in the morning spot urine from all participants. Serum renal functions were evaluated. Results: Thirty-six control and 63 IRpatients were included in the study (68 girls, 29 boys). The mean age of all patients was $13.12 \pm 2.64$ years and no statistically significant difference was found between the two groups in terms of age and gender. Spot urinary NGAL values in the IR group were higher [median $26.35 \mathrm{ng} / \mathrm{mL}$ (range, $7.01-108.7$ )] than the control group [median $19.5 \mathrm{ng} / \mathrm{mL}$ (range, 3.45-88.14)], statistically significant higher $(\mathrm{p}=0.018)$. NGAL/creatinine ratio was also significantly higher in the IR group compared to the control group $(\mathrm{p}=0.018)$.

Conclusions: Obese pediatric patients with IR were shown to have renal injury. Urinary NGAL examination may show early renal injury before development of diabetes.

Keywords: NGAL, renal injury, child, KIM-1, insulin resistance.

Dr. Semra Şen, Celal Bayar University, Medical Faculty, Department of Pediatrics, 45030, Manisa, Turkey +90-(236)-444 4228/ +905057278411

drsemrasen@gmail.com

27.01.2021

07.05.2021

Introduction

The impact of insulin resistance (IR) and obesity on chronic kidney disease (CKD) have been demonstrated [1-4]. Obesity is an important driver of microvascular dysfunction (MVD) [5]. The relationship between hyperglycemia and MVD is bidirectional and constitutes a vicious cycle. Experimental data supported that hyperglycemia causes microvascular disease [6]. MVD contributes to IR and the onset of type 2 diabetes mellitus (T2DM) [5] with a higher prevalence of comorbidities in youth [5-7]. Also, the reduction of hyperglycemia is associated with a reduction of onset and progression of nephropathy. MVD precedes nephropathy[8-10].

The diagnostic standard noninvasive test currently used in clinical practice to predict the onset and monitor the progression of diabetic nephropathy is microalbuminuria measurement. However, this is a sign of early glomerular damage rather than a marker for susceptibility to it. Microalbuminuria has significant limitations in determining disease progression because of the observation that some type 1 diabetes mellitus (T1DM) patients revert to normoalbuminuria without treatment [11]. Also, studies assert that tubulointerstitial injury may precede the appearance of glomerulopathy in diabetic nephropathy [12-13]. Therefore, identification and validation of new biomarkers for early diagnosis of kidney injury may help to predict nephropathy and progression [14]. Tubular injury biomarkers such as urinary NGAL, urinary KIM-1, serum cystatin C, urinary IgG, transferrin were investigated in pediatric and adult patients with T2DM [14-8]. NGAL was defined as an early
} 
renal injury biomarker in type $2 \mathrm{DM}[19]$. The question of our study is whether there is early renal damage before the development of diabetes in obese children with IR showed by this biomarkers.

\section{Methods}

\section{Participants:}

This single-center, cross-sectional, case-control study included children aged between 7-18 years, who applied Manisa Celal Bayar University Hospital, Pediatric Endocrinology and Pediatric outpatient clinic with the complaint of obesity, between June 1, 2017, and May 31, 2018. We divided the patients into two groups; IR group and control group.

Children with type 1 diabetes or obesity with a syndrome (Prader-Willi syndrome, Laurence Moon Biedl syndrome, etc.) or endocrinologic or metabolic pathologies, dietary supplementation were excluded. Children with infection, kidney or other systemic diseases were also excluded from the study.None of the children wereusing antihypertensive and antilipidemic drugs.

\section{Procedures}

\section{1-Clinical and laboratory evaluation}

All obese/overweight patients underwent a thorough physical examination and routine laboratory evaluation, including obesity screening tests (TSH, fT4, fasting glucose, fasting insulin, HOMA-IR), urinalysis, and urinary culture. The assessments were all performed by a single, specially trained clinical research staff. Demographic information, urinary tract abnormalities, urinary tract infections were questioned.

The children and their families were informed about the study and written informed consent was obtained. The local ethics committee (Manisa Celal Bayar University/2015-20478486-217) approved the study in accordance with the Declaration of Helsinki.

\section{2-Classification}

We calculated the BMI as weight $(\mathrm{kg})$ divided by square of height $\left(\mathrm{m}^{2}\right)$. BMI-SDS and BMI percentiles were calculated using age and gender-specific norms published by Neyzi 2006 [20]. Obesity was defined as BMI $\geq 95$ th percentile, and overweight was defined as BMI $\geq 85$ th for age and sex [21].

Insulin resistance was evaluated according to the homeostasis model assessment insulin resistance (HOMA-IR) index which was calculated using the following formula: [Fasting insulin $(\mathrm{mU} / \mathrm{mL}) x$ Fasting glucose $(\mathrm{mg} / \mathrm{dL}) / 405$ ] [22]. Cut-off values for different stages were prepubertal $>2.5$, pubertal $>4[23]$.

Prediabetes was defined according to hemoglobin A1c 5,7-6,4\% or fasting plasma glucose levels $100-126 \mathrm{mg} / \mathrm{dL}$ and/or twohour plasma glucose levels $140-199 \mathrm{mg} / \mathrm{dL}$ according to oral glucose tolerance test (OGT T)[24].

Testing for diabetes was done by measuring hemoglobin $\mathrm{A} 1 \mathrm{c}>6,5 \%$ with a random glucose level $>200 \mathrm{mg} / \mathrm{dL}$ or fasting plasma glucose $>126 \mathrm{mg} / \mathrm{dL}$ or by performing an OGTT, post OGTT 2-hour plasma glucose level $>200 \mathrm{mg} / \mathrm{dL}$ [24]. Patients with diabetes were excluded.

Blood pressure was taken with the appropriate cuff, systolic blood pressure (SBP), and diastolic blood pressure (DBP) were measured twice, after a ten-minute rest, using the right arm and a calibrated sphygmomanometer and the mean of these two BP values were calculated. Hypertension was defined as a value above the 95th percentile for age and height, according to the National Health and Nutrition Examination Survey [25].

An ambulatory blood pressure monitoring (ABPM) device was applied on the same day. ABPM protocol was performed by a singleinvestigator (Ç.Ö). A validated recorder (Contec ABPM50, Germany), was programmed to measure BP at 20-min intervals from $8 \mathrm{AM}$ to $11 \mathrm{PM}$ and at 30-min intervals from $11 \mathrm{PM}$ to $8 \mathrm{AM}$. The most appropriate original standard cuff was selected depending upon the individual's non-dominant arm. The participants were instructed to follow their usual daily activities, to avoid strenuous exercise and shower, to remain still with the forearm extended during measurements, to note the time when they went to bed and arose, and to detach the device $24 \mathrm{~h}$ later. Measurements with systolic BP $<240$ and $>70$ $\mathrm{mm} \mathrm{Hg}$, diastolic $\mathrm{BP}<140$ and $>40 \mathrm{~mm} \mathrm{Hg}$, and diastolic $\mathrm{BP}<$ systolic $\mathrm{BP}$ were accepted as valid [26]. ABPM data with $<$ 30 valid daytime BP measurements and/or $<12$ nighttime measurements were not included [27].

Microalbumin levels were measured in a 24-hour urine sample of all participants.Microalbuminuria was defined as a urinary albumin 30-300 mg/24hours. Microalbuminuric patients were examined for three times. If one result is negative we classifid it as normoalbuminuria[28].

\section{3- Laboratory measurements:}

All blood samples were collected in the morning after at least 8 hours fast (at least 8 hours) for measurements of complete blood count and biochemical parameters, including obesity screening tests (fasting glucose, fasting insulin, HOMA-IR, TSH, fT4, total cholesterol (TC), low-density lipoprotein cholesterol (LDL-C), high-density lipoprotein cholesterol (HDL-C), triglyceride), urea, creatinine (Cr), cystatin C. Estimated glomerular filtration rate (eGFR) was calculated usingthe Schwartz formula [29].

The morning spot urine samples (at least $10 \mathrm{~mL}$ ) were collected from all patients and centrifuged (3000 rpm for five minutes), and the supernatants were frozen at $-80^{\circ} \mathrm{C}$ until analysis. Urinary NGAL (u-NGAL), urinary KIM-1 were measured (ELISA, Human NGAL Platinum ELISA Kit (eBioscience ${ }^{\mathrm{TM}}$, Vienna, Austria)). Urine samples were diluted according to the kit package insert. Urinary NGAL levels were obtained by multiplying the results with 1000 dilution factor. The kit sensitivity is $6.5 \mathrm{pg} / \mathrm{mL}$. The average intra-assay precision CV value of the kit was calculated as 4.0\%. KIM-1 levels in human urine samples were analyzed by Human KIM-1 ELISA Test Kit (BioAssay Works, Ijamsville, USA) with the Enzyme-Linked Immunoassay (ELISA) method. Urine samples were diluted according to the kit package insert. The obtained results were multiplied by six dilution factor, and urinary KIM-1 levels were obtained.

\section{Statistical analysis}

The sample size was calculated using the power analysis method; an effect size of 0.70 and a power of 0.80 (alpha 0.05 ) required a sample of $63 / 36$ people for a case/control study.

Comparison of study variables was first made between patients with IR and control group.Between-group comparison for categorical variables was performed by using the $\chi 2$ test, or Fisher's exact tests. All data were tested for normality using the Kolmogorov-Smirnov test or Shapiro-Wilk. Mann-Whitney U test was used for comparison of not normally distrubuted 
continuous and nonparametric variables, T-test was used for normally distrubuted variables. Univariate correlation analysis was performed between IR participants and healthy controls using Spearman test. Statistical analyses were performed using Statistical Package for Social Sciences 15.0 (SPSS 15.0, Chicago, IL, USA) program. P values $<0.05$ were considered statistically significant.

\section{Results}

In this study, 99 obese $(n=95)$ and overweight $(n=4)$ children/adolescents were evaluated. The median age of the participants was 13 years(range 7-18) and 68 (68.7\%) were female. Our first group consisted of 63 participants with IR (male/female: 17/46; age 13,9 years (range 7-18)). The second group consisted of 36 obese controls without IR (male/female: 14/22; age 12,1 years (8-17)). No statistically significant difference was found between two groups in terms of age, gender and BMI (Table 1). The number of prediabetics was higher in IR group than control group (20 vs. 3$)(p=0.008)$. Insulin resistance group and control group were similar according to hypertension ( $17 \mathrm{vs.} 9 ; \mathrm{p}=0,908)$. Comparison of ABPM data among the two groups resulted in similar hypertension rates and nighttime BP standard deviation score(SDS) values. None of the hypertensives were found to have a secondary cause. The percentages of systolic and diastolic dipping and the rate of nondippers were similar between the two groups. None of the participants had leukocytosis, neutrophilia, thrombocytosis, elevated creatinine or abnormal GFR levels (according to Schwartz) or hypothyroidism.Remaining laboratory analyses are shown in Table 1.

Microalbuminuria median levels were similar in both groups IR ( $\mathrm{p}=0,252)$. Although urinary KIM-1, KIM-1/cre, serum cystatin-C levels were similar between the groups, median urinary NGAL levels [median 26,35 ng/mL (range, $7,01-108,7$ ) vs. $19,5 \mathrm{ng} / \mathrm{mL}$ (range, $3,45-88,14$ ), $\mathrm{p}=0,018$ ] and NGAL/cre levels [median 0,27 (range, 0,05-1,58) vs. 0, 16 (range, 0,01-1,5); $\mathrm{p}=0,018]$ were higher in IR group compared with control group (Table 1).

\section{Discussion}

In daily practice, microalbuminuria is used for renal injury in diabetes. We investigated whether the prediction of renal injury is possible in the IR stage with biomarkers such as serum cystatin C, urinary KIM-1, and urinary NGAL before diabetes developed. This study showed that,NGAL examination may be used as an early biomarker for renal injury in obese IR patients in the absence of diabetes and microalbuminuria. However, there was no significant difference in cystatin and urinary KIM-1 values.

The increasing worldwide rates of obesity in children and adolescents is strongly associated with IR, which in turn is related to some problems, including T2DM [30]. Patients with youth-onset T2DM are at considerable risk for diabetic nephropathy and eventually, renal failure in young adulthood due to microvascular complications [31-3]. Because of the insidious onset of T2DM, the real duration of the disease is often not known; therefore, there is a lower correlation of albumin excretion rate with disease duration than in T1DM [30]. A considerable number of patients with microalbuminuria present at T2DM diagnosis. Screening for microalbuminuria should begin at the time of diagnosis and continue annually [30]. Compared with T1DM, in young-onset T2DM microalbuminuria was observed more frequent with earlier and rapid progression to diabetic nephropathy due to IR [7, 32, 34-7]. Our findings support this hypothesis. IR may be the starting point of diabetic nephropathy. This is study has shown the tubular kidney damage in obese children with IR. Based on this findings, patients may need to be screened with tubular biomarkers at the IR stage before T2DM develops. Experimental studies have shown that reduced insulin sensitivity and hyperinsulinemia are important factors leading to renal injury. It has been excepted that insulin influences renal function primarily at the tubular level, as specific binding of insulin is greatest in thick ascending limb and distal convoluted tubules [38]. There were also studies supporting that insulin acts in the proximal tubules [39]. The experimental number of studies have shown that hyperinsulinemia led to decreased nitric oxide levels, increased transforming growth factor- $\beta 1$ (TGF- $\beta 1$,

insulin-like growth factor-1 (IGF-1), endothelin-1 production and increased oxidative stress [40-4]. These studies could be an explanation for our results.

Neutrophil gelatinase-associated lipocalin is a member of the lipocalin family. Several studies suggest that NGAL might be a marker for a variety of diseases associated with lipid metabolism such as obese-inflammation-induced metabolic syndrome, IR, glucose and lipid metabolism or endothelial dysfunction [45]. NGAL is known to be released from injured renal tubular cells in acute kidney injury before a decrease in the GFR can be detected[46]. Furthermore, urinary NGAL can be used as an early biomarker of diabetic nephropathy [47]. The results of a meta-analysis, which also included pediatric studies, suggest that NGAL in urine can be considered a valuable biomarker for early detection of diabetic nephropathy in the normoalbuminuric stage. It is well known that the pathophysiology and progression of diabetic nephropathy were associated with both glomerular and tubular interstitial damage, and it has been shown that in the absence of glomerular proteinuria, tubular dysfunction can even precede glomerular injury and, thus, microalbuminuria. In recent studies, NGAL concentrations were found to be increased in patients with type 2 dïabetes mellitus with or without albuminuria in subclinical tubular damage $[14,19,48-9]$. However, most childhood studies emphasize the relationship between NGAL and tubular damage in the T1DM population. [50-4]. Also, it was shown that normal range albuminuria does not exclude nephropathy in type 1 diabetic children [55]. This study is the first publication showing the relationship between renal tubular damage and NGAL in childhood with IR before T2DM development.

in adult T2DM patients, urinary KIM-1 levels were found to be significant in showing renal impairment [56-8]. In a study of obese children, urinary KIM-1 was shown to be not significant for determining renal injury [59]. Similarly to KIM-1, studies have demonstrated that cystatin $\mathrm{C}$ was a useful marker of early renal impairment in T2DM adults. In a recent pediatric study, Cystatin C levels were shown to be higher in obese with metabolic syndrome (MetS) compared to those without MetS. In our study, obese children with IR and without IR had similar urinary KIM-1 and serum cystatin C levels [60-1]. These findings suggest that NGAL shows renal effects earlier than KIM-1 and cystatin C.

\section{Limitations}

There are some limitations to our study. The number of our control group was low. We could not see if the renal effects of children with IR were reversible by treatment. Due to the insidious nature of the IR, we were unable to determine the IR 
exposure times of children and their contribution to renal exposure. The gold standard is a biopsy in terms of renal affection, but it is not possible to do it due to the ethical aspect.

\section{Conclusions}

In obese children with normoalbuminuric IR without T2DM, urinary NGAL levels are higher than those without IR and are at risk for early renal damage. Due to the insidious course of T2DM, attention should be paid to renal damage from the IR stage. To the best of our knowledge, this is the first pediatric study showing the tubular damage with NGAL in IR.

\section{Declaration of competing interest}

No author reported a conflict of interest.

\section{Acknowledgments}

This study was funded by Scintific Research Institution of Manisa Celal Bayar University.

Author statement: All the authors have accepted responsibility for the entire content of this submitted manuscript and approved submission. Semra Şen and Deniz Özalp Kizilay wrote the manuscript, developed the theory and performed th computations and also data input. Semra Şen and Deniz Özalp Kizilay conceived the presented idea, developed the theor and performed computations, and provided critical feedback. Semra Sen wrote to the Ethical Committee, supervised the findings of this work and data input. Çınar Özen helped in data input. Fatma Taneli and Raziye Terzi were the laboratory staff. İpek Akil, Betül Ersoy, Pelin Ertan supervised theö manuscriptand provided critical feedback. All authors discussecthe results and contributed to the final manuscript.

Financial disclosure: This study was funded by Scintific Research Institution of Manisa Celal Bayar University

Conflict of interest statement: The authors report no conflictsof interest in this work. The funding organization(s) played no role in the study design; in the collection, analysis, and interpretation of data; in the writing of the report; or in the decision to submit the report for publication.

\section{References}

1. Chen J, Muntner P, Hamm LL, Jones DW, Batuman V, Fonseca V, Whelton PK, He J: The metabolic syndrome and chronic kidney disease in US adults. Ann Intern Med 2004; 140: 167-174.

2. Muntner P, He J, Chen J, Fonseca V, Whelton PK: Prevalence of non-traditional cardiovascular disease risk factors among persons with impaired fasting glucose, impaired glucose tolerance, diabetes, and the metabolic syndrome: analysis of the Third National Health and Nutrition Examination Survey (NHANES III). Ann Epidemiol 2004; 14: 686-695.

3. Wahba IM, Mak RH. Obesity and obesity-initiated metabolic syndrome: mechanistic links to chronic kidney disease. Clin J Am Soc Nephrol 2007;2:550-562.

4. Wang Y, Chen X, Song Y, Caballero B, Cheskin LJ. Association between obesity and kidney disease; a systematic review and meta-analysis. Kidney Int 2008;73:19-33. Epub 2007 Oct 10.

5. Stehouwer CDA. Microvascular Dysfunction and Hyperglycemia: A Vicious Cycle With Widespread Consequences.

Diabetes. 2018;67:1729-1741.

6. Forbes JM, Cooper ME. Mechanisms of diabetic complications. Physiol Rev 2013;93:137-188.

7. Afkarian M. Diabetic kidney disease in children and adolescents. Pediatr Nephrol. 2015; 30:65-74; quiz 70-1.

8. Nathan DM, Genuth S, Lachin J, et al.; Diabetes Control and Complications Trial Research Group. The effect of intensive treatment of diabetes on the development and progression of long-term complications in insulin-dependent diabetes mellitus. N Engl J Med 1993;329:977-986.

9. UK Prospective Diabetes Study (UKPDS) Group. Intensive blood-glucose control with sulphonylureas or insulin compared with conventional treatment and risk of complications in patients with type 2 diabetes (UKPDS 33). Lancet 1998; 352:837-853.

10. Zoungas S, Arima H, Gerstein HC, et al.; Collaborators on Trials of Lowering Glucose (CONTROL) group. Effects of intensive glucose control on microvascular outcomes in patients with type 2 diabetes: a meta-analysis of individual participant data from randomised controlled trials. Lancet Diabetes Endocrinol 2017;5:431-437.

11. Steinke JM, Sinaiko AR, Kramer MS, Suissa S, Chavers BM, Mauer M. International Diabetic Nephopathy Study a. The early natural history of nephropathy in Type 1 Diabetes: III. Predictors of 5-year urinary albumin excretion rate patterns in initially normoalbuminuric patients. Diabetes 2005;54:2164- 2171.

12. Brito PL, Fioretto P, Drummond K, Kim Y, Steffes MW, Basgen JM, Sisson-Ross S, Mauer M. Proximal tubular basement membrane width in insulin-dependent diabetes mellitus. Kidney Int 1998;53:754-761.

13. Thomas MC, Burns WC, Cooper ME. Tubular changes in early diabetic nephropathy. Adv Chronic Kidney Dis 2005;12:177-186.

14. Kapoula GV, Kontou PI, Bagos PG. Diagnostic Accuracy of Neutrophil Gelatinase-Associated Lipocalin for Predicting Early Diabetic Nephropathy in Patients with Type 1 and T2DM: A Systematic Review and Meta-analysis. J Appl Lab Med. 2019;4:78-94.

15. Ding W, Mak RH. Early markers of obesity-related renal injury in childhood. Pediatr Nephrol. 2015;30(1):1-4.

16. Aslan O, Demir M, Koseoglu M. Kidney Injury Molecule Levels in T2DM. J Clin Lab Anal. 2016;30:1031-1036.

17. Żyłkà A, Dumnicka P, Kuśnierz-Cabala B, Gala-Błądzińska A, Ceranowicz P, Kucharz J, Ząbek-Adamska A, Maziarz B, Drożdż R, Kuźniewski M. Markers of Glomerular and Tubular Damage in the Early Stage of Kidney Disease in Type 2 Diabetic Patients. Mediators Inflamm. 2018 Aug 9;2018:7659243.

18. Vijay S, Hamide A, Senthilkumar GP, Mehalingam V. Utility of urinary biomarkers as a diagnostic tool for early diabetic nephropathy in patients with T2DM. Diabetes Metab Syndr. 2018;12:649-652.

19. Li A, Yi B, Liu Y, Wang J, Dai Q, Huang Y, Li YC, Zhang H. Urinary NGAL andRBP Are Biomarkers of Normoalbuminuric Renal Insufficiency in T2DM. J Immunol Res. 2019 Sep 15;2019:5063089.

20. Neyzi O, Furman A, Bundak R, Gunoz H, Darendeliler F, Bas F. Growth references for Turkish children aged 6 to 18 years. Acta Paediatr. 2006 Dec;95(12):1635-41.

21. Kuczmarski RJ, Ogden CL, Guo SS, Grummer-Strawn LM, Flegal KM, Mei Z, Wei R, Curtin LR, Roche AF, Johnson CL. 2000 CDC growth charts for the United States: Methods and development. Vital Health Statistics11 2002;246:1-190. 
22. Matthews DR, Hosker JP, Rudenski AS, et al. Homeostasis model assessment: insulin resistance and beta-cell function from fasting plasma glucose and insulin concentrations in man. Diabetologia. 1985; 28:412-419.

23. Valerio G, Licenziati MR, Iannuzzi A, Franseze A, Siani P, Riccardi G, Rubba P. Insulin resistance and impaired glucose tolerance in obese children and adolescents from southern Italy. Nutr Metab Cardiovasc Dis 2006; 16:279-284.

24. Zeitler P, Arslanian S, Fu J, Pinhas-Hamiel O, Reinehr T, Tandon N, Urakami T, Wong J, Maahs DM. ISPAD Clinical Practice Consensus Guidelines 2018: T2DM in youth. Pediatr Diabetes. 2018;19 Suppl 27:28-46.

25. National High Blood Pressure Education Program Working Group on High Blood Pressure in Children and Adolescents. The fourth report on the diagnosis, evaluation, and treatment of high blood pressure in children and adolescents. Pediatrics. 2004 Aug;114(2 Suppl 4th Report):555-76.

26. Urbina E, Alpert B, Flynn J, Hayman L, Harshfi eld GA, et al. Ambulatory blood pressure monitoring in children and adolescents: recommendations for standard assessment: a scientifi c statement from the American Heart Association Atherosclerosis, Hypertension, and Obesity in Youth Committee of the council on cardiovascular disease in the young and the council for high blood pressure research. Hypertension 2008;52:433 - 51 .

27. Stergiou GS, Alamara C, Drakatos A, Stefanidis CJ, Vazeou A. Prediction of albuminuria by different blood pressure measurement methods in type 1 diabetes: a pilot study. Hypertens Res 2009;32:680-4.

28. Burgert TS, Dziura J, Yeckel C, Taksali SE, Weiss R, Tamborlane W, et al. Microalbuminuria in pediatric obesity: prevalence and relation to other cardiovascular risk factors. Int J Obes (Lond) 2006;30:273-280.

29. Scwartz GJ, Schneider MF, Maier PS, et al. Improved equations estimating GFR in children with chronic kidney disease using an immunonephelometric determination of cystatin C. Kidney Int. 2012;82:445-453.

30. Bogdanović R. Diabetic nephropathy in children and adolescents. Pediatr Nephrol. 2008 ;23:507-25.

31. Yokoyama H, Okudaira M, Otani T, Watanabe C, Takaike H, Miuira J, Yamada H, Mutou K, Satou A, Uchigata Y, Iwamoto Y. High incidence of diabetic nephropathy in early-onset Japanese NIDDM patients. Diabetes Care 1998; 21:1080 1085 .

32. Yokoyama H, Okudaira M, Otani T, Sato A, Miura J, Takaike H, Yamada H, Muto K, Uchigata Y, Ohashi Y, Iwamoto Y. Higher incidence of diabetic nephropathy in type 2 than in type 1 diabetes in early-onset diabetes in Japan. Kidney Int. 2000;58:302-311.

33. Krakoff J, Lindsay R, Looker HC, Nelson RG, Hanson RL, Knowler WC. Incidence of retinopathy and nephropathy in youth-onset compared with adult-onset type 2 diabetes. Diabetes Care 2003; 26:76-81.

34. Maahs DM, Snively BM, Bell RA, Dolan L, Hirsch I, Imperatore G, Linder B, Marcovina SM, Mayer-Davis EJ, Pettitt DJ, Rodriguez BL, Dabelea D. Higher prevalence of elevated albumin excretion in youth with type 2 than type 1 diabetes: the SEARCH for Diabetes in Youth study. Diabetes Care. 2007; 30:2593-8.

35. Scott A, Toomath R, Bouchier D, Bruce R, Crook N, Carroll D, Cutfield R, Dixon P, Doran J, Dunn P, Hotu C, Khant M, Lonsdale M, Lunt H, Wiltshire E, Wu D. First national audit of the outcomes of care in young people with diabetes in New Zealand: high prevalence of nephropathy in Maori and Pacific Islanders. The N Z Med J. 2006;119:U2015.

36. Dart AB, Sellers EA, Martens PJ, Rigatto C, Brownell MD, Dean HJ. High burden of kidney disease in youth-onset type 2 diabetes. Diabetes Care. 2012;35:1265-1271.

37. Bjornstad P, Snell-Bergeon JK, Rewers M, Jalal D, Chonchol MB, Johnson RJ, Maahs DM. Early diabetic nephropathy: a complication of reduced insulin sensitivity in type 1 diabetes. Diabetes Care. 2013;36:3678-3683.

38. Butlen D, Vadrot S, Roseau S, Morel F. Insulin receptors along the rat nephron: [ $125 \mathrm{I}]$ insulin binding in microdissected glomeruli and tubules. Pflügers Arch 1988; 412: 604-612.

39. Baum M. Insulin stimulates volume absorption in the rabbit proximal convoluted tubule. J Clin Invest 1987; $79: 1104$ 1109.

40. Morrisey K, Evans RA, Wakefield L, Phillips AO: Translational regulation of renal proximal tubular epithelial cell transforming growth factor-betal generation by insulin. Am J Pathol 2001; 159: 1905-1915.

41. Wang S, Denichilo M, Brubaker C, Hirschberg R. Connective tissue growth factor in tubulointerstitial injury of diabetic nephropathy. Kidney Int 2001; 60: 96-105. (RAT)

42. Kohan DE. Endothelins in the kidney: physiology and pathophysiology. Am J Kidney Dis 1993; 22: 493-510.

43. Marsen TA, Schramek H, Dunn MJ: Renal actions of endothelin: linking cellular signaling pathways to kidney disease. Kidney Int 1994; 45: 336-344.

44. Sarafidis PA, Ruilope LM. Insulin resistance, hyperinsulinemia, and renal injury: mechanisms and implications. Am J Nephrol. 2006;26:232-44.

45. Li B, Huang J. [Progress in research on the relationship between NGAL and metabolic syndrome]. Zhong Nan Da Xue Xue Bao Yi Xue Ban. 2015;40:1264-9.

46. Mishra J, Ma Q, Prada A,MitsnefesM, Zahedi K, Yang J, Barasch J, Devarajan P. Identification of neutrophil gelatinaseassociated lipocalin as a novel early urinary biomarker for ischemic renal injury. J Am Soc Nephrol 2003; 14:2534-43 47. Bolignano D, Lacquaniti A, Coppolino G, Donato V, Fazio MR, Nicocia G, Buemi M. Neutrophil gelatinase-associated lipocalin as an early biomarker of nephropathy in diabetic patients. Kidney Blood Press Res2009; 32:91-98

48. Kaul A, Behera MR, Rai MK, Mishra P, Bhaduaria DS, Yadav S, et al. Neutrophil gelatinase-associated lipocalin: as a predictor of early diabetic nephropathy in T2DM. Indian J Nephrol 2018;28:53-60.

49. Bolignano D, Lacquaniti A, Coppolino G, Donato V, Fazio MR, Nicocia G, et al. Neutrophil gelatinase-associated lipocalin as an early biomarker of nephropathy in diabetic patients. Kidney Blood Press Res 2009;32:91-8. 50.Ucakturk A, Avci B, Genc G, Ozkaya O, Aydin M. Kidney injury molecule-1 and neutrophil gelatinase associated lipocalin in normoalbuminuric diabetic children. J Pediatr Endocrinol Metab 2016;29:145-51.

51. Demir K, Abaci A, Kume T, Altincik A, Catli G, Bober E. Evaluation of neutrophil gelatinase-associated lipocalin in normoalbuminuric normotensive type 1 diabetic adolescents. J Pediatr Endocrinol Metab 2012;25:517-23.

52. Hafez MH, El-Mougy FA, Makar SH, Abd El Shaheed S. Detection of an earlier tubulopathy in diabetic nephropathy among children with normoalbuminuria. Iranian J Kidney Dis 2015;9:126-31. 
53. Soltysiak J, Skowronska B, Fichna P, Stankiewicz W, Lewandowska-Stachowiak M, Ostalska-Nowicka D, et al. Neutrophil gelatinase-associated lipocalin and cathepsin L as early predictors of kidney dysfunction in children with type 1 diabetes. Endokrynologia Polska 2014;65: 479-84.

54. Papadopoulou-Marketou N, Margeli A, Papassotiriou I, Chrousos GP, Kanaka-Gantenbein C, Wahlberg J. NGAL as an early predictive marker of diabetic nephropathy in children and young adults with type 1 diabetes mellitus. J Diabetes Res 2017;2017:7526919.

55. Zachwieja J, Soltysiak J, Fichna P, Lipkowska K, Stankiewicz W, Skowronska B, et al. Normal-range albuminuria does not exclude nephropathy in diabetic children. Pediatr Nephrol 2010;25:1445-51.

56. Siddiqui K, Joy SS, Al-Rubeaan K. Association of urinary monocyte chemoattractant protein-1 (MCP-1) and kidney injury molecule-1 (KIM-1) with risk factors of diabetic kidney disease in type 2 diabetes patients. Int Urol Nephrol. 2019;51:1379-1386.

57. Colombo M, Looker HC, Farran B, Hess S, Groop L, Palmer CNA, Brosnan MJ, Dalton RN, Wong M, Turner C, Ahlqvist E, Dunger D, Agakov F, Durrington P, Livingstone S, Betteridge J, McKeigue PM, Colhoun HM; SUMMIT Investigators. Serum kidney injury molecule 1 and $\beta(2)$-microglobulin perform as well as larger biomarker panels for prediction of rapid decline in renal function in type 2 diabetes. Diabetologia. 2019;62:156-168.

58. de Carvalho JA, Tatsch E, Hausen BS, Bollick YS, Moretto MB, Duarte T, Duarte MM, Londero SW, Premaor MO Comim FV, Delanghe JR, Moresco RN. Urinary kidney injury molecule-1 and neutrophil gelatinase-associated lipocalin indicators of tubular damage in normoalbuminuric patients with type 2 diabetes. Clin Biochem. 2016;49:232-6.

59. Bostan Gayret Ö, Taşdemir M, Erol M, Tekin Nacaroğlu H, Zengi O, Yiğit Ö. Are there any new reliable markers to detect renal injury in obese children? Ren Fail. 2018;40:416-422.

60. Zeng XF, Lu DX, Li JM, Tan Y, Li Z, Zhou L, Xi ZQ, Zhang SM, Duan W. Performance of urinary neutrophil gelatinase-associated lipocalin, clusterin, and cystatin $\mathrm{C}$ in predicting diabetic kidney disease and diabetic microalbuminuria: a consecutive cohort study. BMC Nephrol. 2017;18:233.

61. Jeon YL, Kim MH, Lee WI, Kang SY. Cystatin C as an early marker of diabetic nephropathy in patients with type 2 diabetes. Clin Lab. 2013;59(11-12):1221-9.

Table 1: Sociodemographic characteristics, laboratory findings, urinary NGAL, urnary KIM-1 and serum cystatin-C levels of obese insulin resistance group and control group

\begin{tabular}{|c|c|c|c|}
\hline & Insulin Resistance group $(n=6 \overline{3})$ & Control group $(\mathrm{n}=36)$ & $p$ \\
\hline Age median (range) (years) & $13,9(7-18)$ & $12,1(8-17)$ & 0,061 \\
\hline Gender (M/F) & $17 / 46$ & $14 / 22$ & 0,263 \\
\hline BMI $\left(\mathrm{kg} / \mathrm{m}^{2}\right)$ & $29,8(17-42)$ & $28,1(20-39)$ & 0,063 \\
\hline SBP (mmHg) median (range) & $115(\overline{80-150)}$ & $115(90-160)$ & 0,923 \\
\hline DBP (mmHg) median (range) & $70(50-100)$ & $70(50-100)$ & 0,587 \\
\hline Prediabetes (n) & 20 & 3 & 0,008 \\
\hline $\begin{array}{l}\text { Fasting glucose median (range) } \\
(\mathrm{mg} / \mathrm{dL})\end{array}$ & $86(67-105)$ & $84(70-100)$ & 0,486 \\
\hline Fasting insulin median (range) & $30,30(17-60)$ & $16,05(8-21)$ & 0,000 \\
\hline HOMA-IR & $6,06(4-14)$ & $3,3(2-4)$ & 0,000 \\
\hline Blood Urea median (range) $(\mathrm{mg} / \mathrm{dL})$ & $21,7(13-36)$ & $24(15-34)$ & 0,402 \\
\hline $\begin{array}{l}\text { Blood creatinine }(\mathrm{mg} / \mathrm{dL}) \text { median } \\
\text { (range) }\end{array}$ & $0,56(0,1-1)$ & $0,5(0,1-1)$ & 0,717 \\
\hline Uric acid (mg/dL) & $5(1,60-9,60)$ & $4,85(3,20-7,10)$ & 0,155 \\
\hline eGFR median (range) (Schwartz) & $119,5(83,50-231)$ & $120,20(70,7-178,10)$ & 0,608 \\
\hline
\end{tabular}




\begin{tabular}{|c|c|c|c|}
\hline$\left(\mathrm{mL} / \mathrm{min} / 1.73 \mathrm{~m}^{2}\right)$ & & & \\
\hline Triglycerides(mg/dL) & $114(44-389)$ & $96(42-257)$ & 0,167 \\
\hline Total cholesterol (mg/dL) & $165(103-254)$ & $149,5(91-219)$ & 0,062 \\
\hline HDL-c (mg/dL) & $45,1(32-79)$ & $47,05(26-68)$ & 0,417 \\
\hline LDL-c (mg/dL) & $92(19-187)$ & $78,5(34-131)$ & 0,077 \\
\hline TSH (mIU / L) & $2,5(1,05-5,8)$ & $2,55(0,95-5,6)$ & 0,954 \\
\hline $\begin{array}{l}\text { Urinary NGAL median (range) } \\
(\mathrm{pg} / \mathrm{mL})\end{array}$ & $26,35(7,01-108,7)$ & $19,5(3,45-88,14)$ & 0,018 \\
\hline NGAL/cre median (range) pg/mg & $0,27(0,05-1,58)$ & $0,16(0,01-1,5)$ & 0,018 \\
\hline KIM-1 median (range) (pg/mL) & $0,84(0-2,09)$ & $0,85(0-6,18)$ & 0,789 \\
\hline KIM-1/cre median (range) & $0,01(0,00-0,03)$ & $0,008(0,00-0,06)$ & 0,570 \\
\hline Cystatin C (mg/L) median (range) & $0,82(0,28-1)$ & $0,84(0,7-1)$ & 0,154 \\
\hline $\begin{array}{l}\text { Cystatin C eGFR median (range) } \\
m L / d k / 1.73 \mathrm{~m} 2\end{array}$ & $93,7(72,20-170,4)$ & $90,75(71,5-110,5)$ & 0,138 \\
\hline eGFR median (range) & $151,05(80,3-361,1)$ & $180,8(85,7-417,02)$ & 0,141 \\
\hline $\begin{array}{l}\text { Urinary protein/creatinine } \\
\text { Median mg/gr (range) }\end{array}$ & $0,04(0,02-0,16)$ & $0,04(0,02-0,61)$ & 0,994 \\
\hline $\begin{array}{l}\text { Microalbuminuria } \mathrm{mg} / 24 \mathrm{~h} \text { median } \\
\text { (range) }\end{array}$ & $6(0-29)$ & $6,8(0-29,9)$ & 0,252 \\
\hline
\end{tabular}

BMI, body mass index; DBP, diastolic blood pressure; GlcT01, fasting glucose; HDL-c, high density lipoprotein cholesterol;

HOMA-IR, homeostatic model assessmensst of insulin resistance; InsT0 ${ }^{1}$, fasting insülin;KIM-1: kidney injury molecule-1;

LDL-c, low density lipoprotein cholesterol; NGAL: Neutrophil gelatinase-associated lipocalin; SBP, systolic blood pressure;

SDS, standard deviation score; TG, triglycerides. 